\title{
Artifacts and Pheromone Blends from Nezara spp. and Other Stink Bugs (Heteroptera: Pentatomidae)
}

\author{
J. R. Aldrich
}

USDA-ARS, Insect Chemical Ecology Laboratory, Agricultural Research Center-West, B-007, Beltsville, Maryland 20705, U.S.A.

H. Numata

Department of Biology, Faculty of Science, Osaka City University, Sumiyoshi, Osaka 558, Japan

M. Borges

EMBRAPA/CENARGEN, Centro Nacional de Recuros Geneticos e Biotechnologia, CEP 70.770 Brasilia DF, Brazil

F. Bin

Instituto di Entomologia Agraria, University Degli Studi di Perugia, 06100 Perugia, Italy

G. K. Waite

Queensland Dept. of Primary Industries, Maroochy Horticultural Research Station, Nambour Qld 4560, Australia

and

W. R. Lusby

USDA-ARS, Insect Neurobiology and Hormone Laboratory, Agricultural Research Center-East, B-467, Beltsville, Maryland 20705, U.S.A.

Z. Naturforsch. 48c, 73-79 (1993); received July 21, 1992

Hemiptera, Euschistus, Podisus, Attractant, Bisabolene

Isomeric compounds reportedly released by mature males of Nezara viridula as attractants for conspecific females are evidently artifacts formed by dimerization of $(E)$-4-oxo-2-hexenal. Additional analyses of the male-specific volatiles from Italian, Australian, Brazilian, and Japanese populations of $N$. viridula verify that at least two distinctive pheromone strains exist, but an active synthetic pheromone has not yet been developed. Analyses of volatiles from $N$. antennata and Acrosternum aseadum males are also reported showing that the native Japanese Nezara sp., and species in the sister genus Acrosternum, produce species-specific blends based on the same compounds as $N$. viridula: $(Z)$ - $\alpha$-bisabolene (1-methyl-4-(1,5-dimethyl- $(Z)-1,4-$ hexadienyl)-cyclohexene), and trans- and cis-1,2-epoxides of (Z)- $\alpha$-bisabolene. The trans-/cis1,2 -epoxide ratio of $N$. antennata is within the range found for most $N$. viridula populations, but the blend from Japanese $N$. viridula males deviates radically from those of other conspecific populations.

\section{Introduction}

Nezara viridula (Heteroptera: Pentatomidae) is a native of the Ethiopian Region [1,2], but is now a serious pest in most subtropical areas of the world. This insect, known by various common names, is called the southern green stink bug (SGSB) in the United States. As the common name suggests, stink bugs have highly developed scent glands that produce irritating secretions to defend themselves against predators [3]. The imma-

Reprint requests to Dr. J. R. Aldrich.

Verlag der Zeitschrift für Naturforschung,

D-W-7400 Tübingen

0939-5075/93/0100-0073\$ \$01.30/0 tures (nymphs) possess two large dorsal abdominal glands, whereas the adults emit their allomones from metathoracic scent glands. In addition to their repugnant defensive scretion, males release a pheromone that attracts females and males, as well as conspecific nymphs [4]. Although the glandular source of the pheromone has not been positively identified, aeration extracts of laboratory-reared SGSB males (U.S. strain) were active in the field, and attraction of the tachinid parasite, Trichopoda pennipes (Diptera), indicated that this fly uses the pheromone as a host-finding kairomone [5]. The major male-specific volatiles of $N$. viridula [5-7], and species in the sister genus Acrosternum [7], include $(Z)$ - $\alpha$-bisabolene $(\mathrm{MW}=204) \quad(1$-methyl- 
4-(1,5-dimethyl-(Z)-1,4-hexadienyl)-cyclohexene) and 1,2-epoxides of $(Z)-\alpha$-bisabolene $(\mathrm{MW}=220)$. The abundance of the cis-epoxide isomer released by $N$. viridula males varies, depending on the geographic origin of the bugs, from being undetectable [6] to being present at an equivalent concentration to that for the trans-epoxide isomer [7]. However, French researchers reported that the $220 \mathrm{MW}$ volatiles from SGSB males were not attractive to females in a laboratory bioassay, whereas a pair of unidentified $224 \mathrm{MW}$ isomers from males did attract females $[8,9]$. Here we report on the identity of these $224 \mathrm{MW}$ compounds, and on additional pheromone analyses for $N$. viridula from Brazil, Italy, Australia, and Japan. We also report the results of pheromone analyses for the native Japanese species, $N$. antennata, and the South American species, A. aseadum.

\section{Materials and Methods}

Nezara viridula used for this study were from colonies started from insects collected near Stoneville, Mississippi (JRA); Brasilia and Londrina, Brazil (MB); Perugia, Italy (FB); Nambour, Queensland, Australia (GKW); and Kamitondacho, Wakayama, Japan (HN). Acrosternum aseadum and Podisus connexivus were collected near Brasilia (MB), and $N$. antennata was collected in Kyoto City, Japan (HN) [10]. Nezara, Acrosternum, and Podisus colonies were maintained after previously described methods $[5,10,11]$ in the laboratories of the countries of origin. Euschistus servus adult males were collected in pheromonebaited traps near the Beltsville Agricultural Research Center [12].

Groups of 4-40 sexually mature males of $\mathrm{Ne}$ zara spp., A. aseadum, and E. servus were aerated in the respective laboratories as previously described $[5,7]$. Heptane or hexane were used instead of $\mathrm{CH}_{2} \mathrm{Cl}_{2}$ for extraction of most Nezara and Acrosternum entrained samples because bisabolene derivatives are unstable in acidic solvents, and the relatively low volatility of heptane reduced the risk of evaporation during shipment.

Pentatomid nymphs possess two large dorsal abdominal glands [3] whose contents are shed with the exuviae at ecdysis $[11,13]$. The exuviae $(\leq 24 \mathrm{~h}$ after ecdysis) from ca. $50 \mathrm{P}$. connexivus nymphs (first-to-fifth-instar) were extracted in $1 \mathrm{ml}$ of
$\mathrm{CH}_{2} \mathrm{Cl}_{2}$, and the secretion from the posterior dorsal abdominal gland in the exuviae from one fifthinstar $N$. viridula nymph was collected in a micropipette and extracted in $100 \mu \mathrm{l}$ of $\mathrm{CH}_{2} \mathrm{Cl}_{2}$ for the analyses reported here.

Samples prepared in the U.S., Japan, Italy, and Brazil were analyzed by gas chromatography (GC) in the U.S. on a bonded methyl silicone column $\left(0.25 \mu \mathrm{m}\right.$ film, $14 \mathrm{~m} \times 0.25 \mathrm{~mm}$ ID; DB-1 ${ }^{\mathrm{TM}}, \mathrm{J} \& \mathrm{~W}$ Scientific, Folsom, CA) in a Varian $3700 \mathrm{GC}$ with helium as carrier $(40 \mathrm{~cm} / \mathrm{sec})$, a temperature program from $45^{\circ} \mathrm{C}$ for $2 \mathrm{~min}$ to $230^{\circ} \mathrm{C}$ at $15^{\circ} /$ min, a flame ionization detector (FID), and a Shimadzu C-R 3 A recorder. Some Brazilian samples were analyzed by $\mathrm{GC}$ in the Brasilia laboratory under conditions identical to those for U.S. analyses except that a $30 \mathrm{~m} \mathrm{DB}-1$ column was used. The Australian samples were analyzed on a DB- $5^{\mathrm{TM}}$ column $(0.25 \mu \mathrm{m}$ film; $30 \mathrm{~m} \times 0.25 \mathrm{~mm}$ ID; J\&W Scientific) in a Hewlett-Packard 5890 $\mathrm{GC} / 3392 \mathrm{~A}$ Integrator with helium as carrier, programmed from $45^{\circ} \mathrm{C}$ for $2 \min$ to $260^{\circ} \mathrm{C}$ at $15^{\circ} /$ min, and a FID.

Electron impact mass spectra (EI-MS) were obtained in the U.S. laboratory for samples prepared in the U.S., Japan, Italy, and Brazil. Most extracts were analyzed using a Finnigan 4510 GC-MS equipped with an INCOS Data System, at $70 \mathrm{eV}$, and a $30 \mathrm{~m}$ DB-1 column, programmed from $60^{\circ} \mathrm{C}$ for $2 \mathrm{~min}$ to $250{ }^{\circ} \mathrm{C}$ at $5^{\circ} / \mathrm{min}$. Samples of $N$. antennata, and $N$. viridula from Londrina, Brazil, were analyzed using a Hewlett Packard 5971 GC-MS instrument at $70 \mathrm{eV}$, with a $\mathrm{HP}-5^{\mathrm{TM}}$ column $(0.11 \mu \mathrm{m}$ film; $25 \mathrm{~m} \times 0.2 \mathrm{~mm}$ ID), programmed from $50{ }^{\circ} \mathrm{C}$ for $2 \mathrm{~min}$ to $250^{\circ} \mathrm{C}$ at $15^{\circ}$ / min. Aeration extracts of Australian N. viridula were analyzed at $70 \mathrm{eV}$ using a Finnigan 1020 GC-MS with a $30 \mathrm{~m} \mathrm{DB}-5$ column $(0.11 \mu \mathrm{m} \times$ $0.2 \mathrm{~mm}$ ), programmed from $40{ }^{\circ} \mathrm{C}$ for $2 \mathrm{~min}$ to $260{ }^{\circ} \mathrm{C}$ at $10^{\circ} / \mathrm{min}$.

Compounds identified by mass spectral data were cross-checked by GC and MS comparisons to authentic standards. Linalool, $n$-tridecane, and $n$-nonadecane were obtained from Aldrich Chemical Co. (Milwaukee, WI); (E)-2-decenal was purchased from Bedoukian Research Inc. (Danbury, $\mathrm{CN})$. ( $Z$ )- $\alpha$-Bisabolene was synthesized according to a published procedure [14], and the corresponding cis- and trans-1,2-epoxides were synthesized as part of an earlier investigation [7, 15]. 
(E)-4-Oxo-2-hexenal was synthesized according to Ward and Van Dorp [16]. To produce dimers of (E)-4-oxo-2-hexenal $c a$. $20 \mu$ l of the neat material was flame-sealed in a capillary tube, placed in an oven at $95^{\circ} \mathrm{C} / 22 \mathrm{~h}$, and the heat-treated material was dissolved in $\mathrm{CH}_{2} \mathrm{Cl}_{2}$ for $\mathrm{GC}$ and $\mathrm{GC}-\mathrm{MS}$ analyses.

\section{Results}

After Pavis and Malosse [8] reported that a pair of $224 \mathrm{MW}$ isomers from $N$. viridula males were attractive to conspecific females, we (JRA \& WRL) manually entered artificial EI-MS matching the reported spectra for these compounds [9] into the computerized mass spectral library of our Finnigan 4510 GC-MS. A computer search of the EI-MS recorded for a pooled aeration sample of ca. 250 SGSB males failed to produce a match for either EI-MS reported by Pavis [5], but the artificially created spectra were never deleted from the library.

Later, in the course of other semiochemical investigations [10-13], best-fit matches for the artificial spectra of these $224 \mathrm{MW}$ isomers were re- trieved from the library for compounds eluting at retention time $(\mathrm{RT})=9.5 \mathrm{~min}$ and $\mathrm{RT}=9.6 \mathrm{~min}$ in extracts of exuviae from $N$. viridula and $P$. connexivus nymphs (Fig. $1 \mathrm{~A}$ and $\mathrm{B}$; compounds $\mathbf{4}$ and 5), and in an aeration extract of adult E. servus males (not shown). The exuvial extracts contained substantial amounts of (E)-4-oxo-2-hexenal (Fig. 1; compound 1, MW=112) [11, 13], and the E. servus aeration extract was contaminated with metathoracic scent gland secretion also containing (E)-4-oxo-2-hexenal [unpublished data]. Therefore, it was suspected that the presence of $224 \mathrm{MW}$ isomers might be due to dimerization of $(E)$-4-oxo2-hexenal. Analysis of heat-treated synthetic (E)-4-oxo-2-hexenal showed that the relative abundance of 1 was greatly reduced by heating, with the concomitant appearance of later eluting compounds, including components $\mathbf{4}$ and $\mathbf{5}$ (Fig. 1C). The EI-MS of components 4 and $\mathbf{5}$ derived from $(E)$-4-oxo-2-hexenal are virtually identical to those for the compounds of matching RT in the nymphal $N$. viridula extract (Fig. 2), and the corresponding components in the $P$. connexivus and $E$. servus extracts (not shown). The mass spectra reported here (Fig. 2) for the (E)-4-oxo-2-

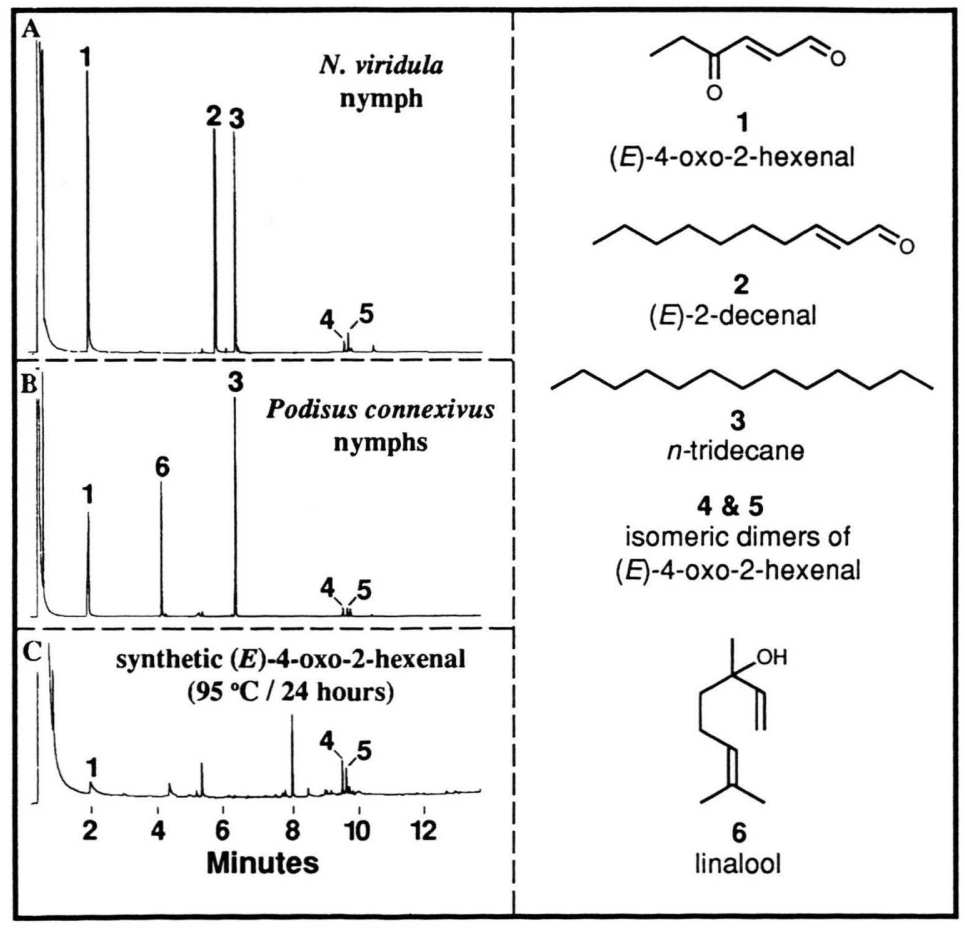

Fig. 1. Gas chromatograms of (A) $\mathrm{Ne}$ zara viridula posterior dorsal abdominal secretion extract from the exuviae of a single fifth-instar nymph, (B) Podisus connexivus exuvial extract from ca. 50 first- to fifth-instar nymphs and, (C) an extract of heat-treated (E)-4-oxo2-hexenal. $(1=(E)$-4-oxo-2-hexenal, 2 $=(E)$-2-decenal, $3=n$-tridacane, 4 and $5=$ isomeric dimers of $(E)$-4-oxo2-hexenal, and $6=$ linalool). 


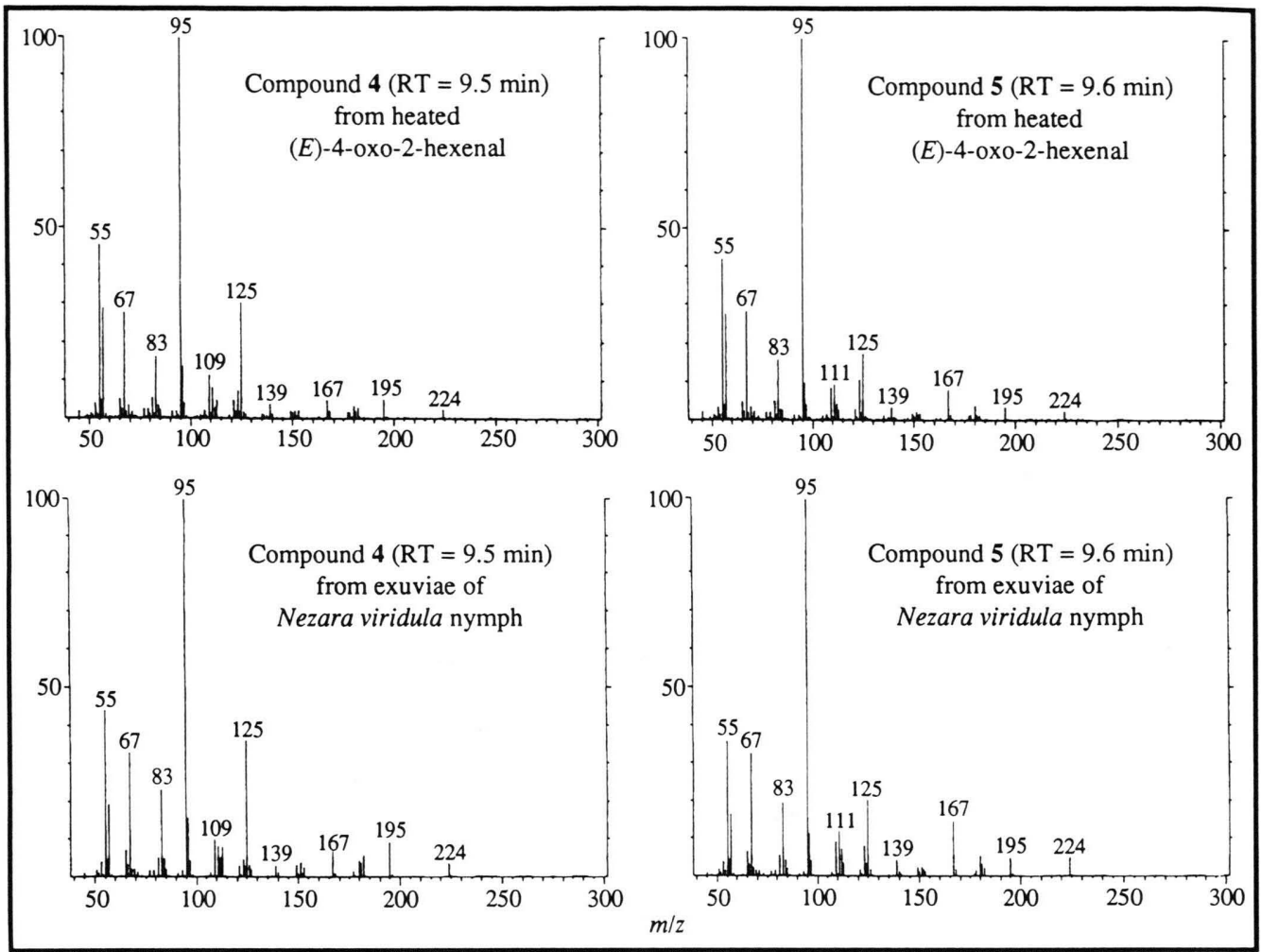

Fig. 2. Electron impact mass spectra of isomeric dimers (Fig. 1, compounds 4 and 5) from heat-treated (E)-4-oxo2-hexenal (top), and Nezara viridula posterior dorsal abdominal gland secretion (bottom).

hexenal dimers have less intense low molecular weight ions than the mass spectra reported by Pavis [9], but this discrepancy is due to a feature of the Finnigan INCOS software whereby the recorded intensities of ions are a function of the square root of ion mass times intensity.

Identified compounds that are produced exclusively by adult males of Nezara and Acrosternum spp. are listed in Table I. An earlier investigation verified that the blend of male-specific volatiles from a U.S. strain of $N$. viridula is an attractant pheromone [5]. Pheromone blends for 5 additional geographically isolated populations of $N$. viridula, and for $N$. antennata and A. aseadum, are reported here. Samples used to calculate the percentages of compounds reported in Table I contained up to $24 \%$ contamination from metathoracic scent gland secretion so that sums of the male-specific components for the species range from $95.2 \%$ (Brasilia N. viridula) to $75.6 \%$ (A. aseadum). However, the proportions of the sesquiterpenoid components within each population are relatively uniform. For $N$. viridula populations from Italy, Australia and Brazil, ratios of trans-/cis- $(Z)-\alpha$-bisabolene-1,2epoxides ranged from 2.16-4.67. Nezara viridula males from Wakayama, Japan, produced a significantly different blend, containing equivalent amounts of the epoxide isomers (trans-/cis-epoxide ratio $=0.82$ ). The concentration of $n$-nonadecane in samples from $N$. viridula populations (2.2$20.6 \%$ ) was much more variable than were concentrations of sesquiterpenoids. The volatiles from $N$. antennata males resembled the blends from the non-Japanese populations of $N$. viridula (Fig. 3), with a trans-/cis-epoxide ratio $=4.08$; however, the concentrations of $(Z)$ - $\alpha$-bisabolene and $(E)$-nerolidol from $N$. antennata males were higher than for $N$. viridula blends, and $n$-nonadecane was barely detectable in $N$. antennata extracts. Finally, the single aeration sample for $A$. aseadum males contained the same sesquiterpenoids as for Nezara spp., but in distinctly different proportions: $(Z)$ - 
J. R. Aldrich et al. · Artifacts and Pheromone Blends from Nezara spp. and Other Stink Bugs

Table I. Pheromone blends ( $\% \pm \mathrm{SEM})$ of five Nezara viridula populations, Nezara antennata, and Acrosternum aseadum.

\begin{tabular}{lcccccccc}
\hline $\begin{array}{l}\text { Species } \\
\text { (Source) }\end{array}$ & $n$ & $\begin{array}{l}\text { Total } \\
\text { Males }\end{array}$ & $\begin{array}{l}(Z)-\alpha- \\
\text { Bisabolene }\end{array}$ & $\begin{array}{l}(E)- \\
\text { Nerolidol }\end{array}$ & $\begin{array}{l}\text { trans- } \\
\text { Epoxide }\end{array}$ & $\begin{array}{l}\text { cis- } \\
\text { Epoxide }\end{array}$ & $\begin{array}{l}n \text {-Nona- } \\
\text { decane }\end{array}$ & $\begin{array}{l}\text { trans/cis } \\
\text { Ratio }\end{array}$ \\
\hline $\begin{array}{l}N . \text { viridula } \\
\text { (Perugia, Italy) }\end{array}$ & 6 & 162 & $29.3 \pm 2.3$ & - & $33.1 \pm 2.0$ & $15.3 \pm 1.2$ & $13.7 \pm 2.1$ & 2.16 \\
$\begin{array}{l}N . \text { viridula } \\
\text { (Nambour, Australia) }\end{array}$ & 2 & 30 & $22.7 \pm 1.0$ & $0.4 \pm 0.1$ & $42.1 \pm 0.4$ & $10.8 \pm 0.8$ & $2.2 \pm 0.5$ & 3.90 \\
$\begin{array}{l}N . \text { viridula } \\
\text { (Brasilia, Brazil) }\end{array}$ & 5 & 66 & $21.8 \pm 3.2$ & - & $45.3 \pm 3.3$ & $19.9 \pm 2.6$ & $8.2 \pm 1.4$ & 2.28 \\
$\begin{array}{l}N . \text { viridula } \\
\text { (Londrina, Brazil) }\end{array}$ & 2 & 4 & $28.2 \pm 0.8$ & - & $31.3 \pm 1.3$ & $6.7 \pm 2.1$ & $20.6 \pm 2.1$ & 4.67 \\
$\begin{array}{l}N . \text { viridula } \\
\text { (Wakayama, Japan) }\end{array}$ & 7 & 183 & $23.6 \pm 4.3$ & $1.7 \pm 0.4$ & $23.0 \pm 3.0$ & $28.0 \pm 2.5$ & $5.0 \pm 0.8$ & 0.82 \\
$\begin{array}{l}N . \text { antennata } \\
\text { (Kyoto, Japan) }\end{array}$ & 10 & 250 & $46.7 \pm 2.0$ & $3.5 \pm 0.4$ & $31.0 \pm 1.0$ & $7.6 \pm 0.2$ & - & 4.08 \\
$\begin{array}{l}\text { A. aseadum } \\
\text { Brasilia, Brazil) }\end{array}$ & 1 & 38 & 7.0 & - & 6.4 & 62.2 & - & 0.10 \\
\hline
\end{tabular}

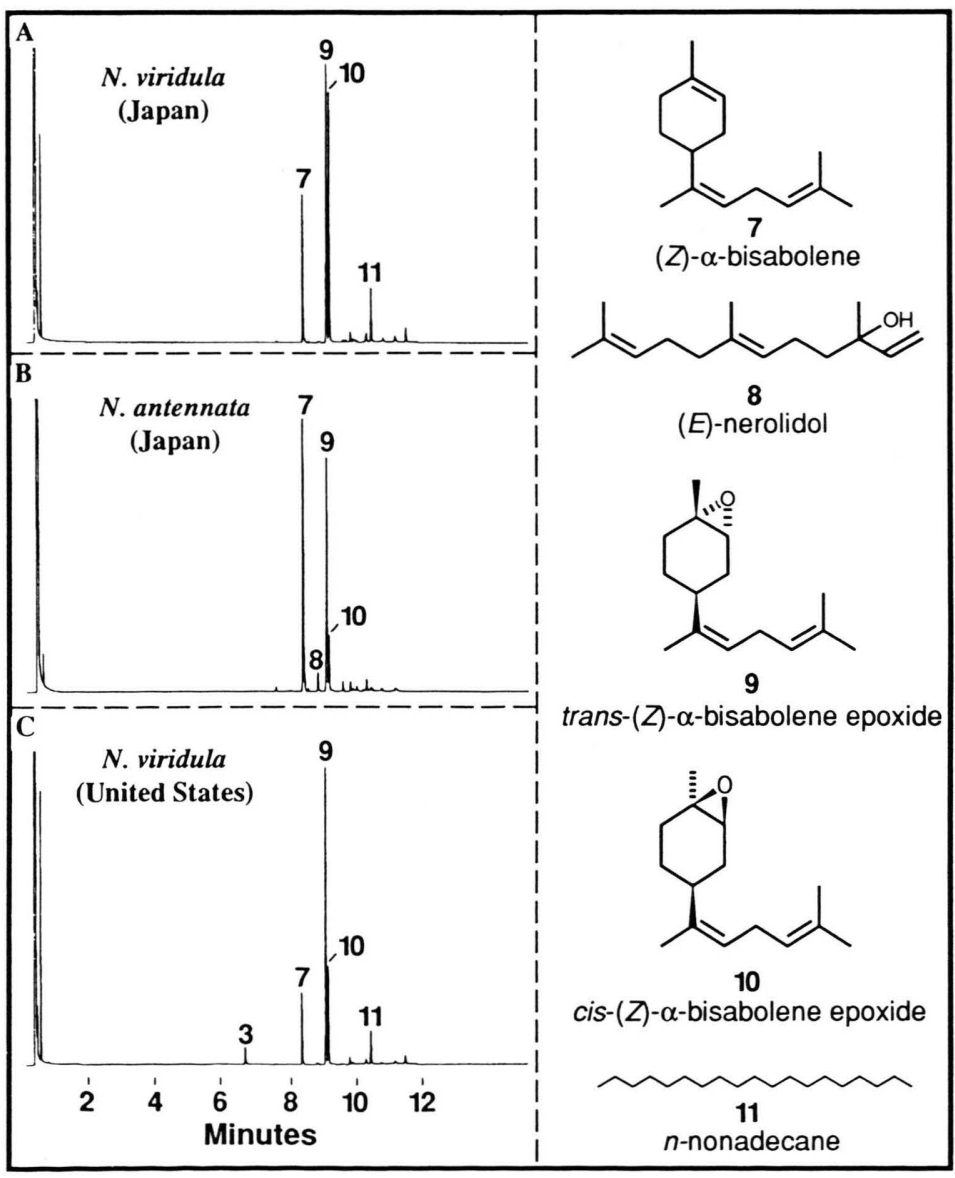

Fig. 3. Gas chromatograms of male-specific volatiles entrained from (A) Nezara viridula from Kamitondo-cho, Wakayama, Japan, (B) Nezara antennata from Kyoto, Wakayama, Japan, and (C) $\mathrm{Ne}$ zara viridula from Stoneville, Mississippi, United States. (30 males/sample; $7=$ $(Z)$ - $\alpha$-bisabolene, $8=(E)$-nerolidol, $9=$ trans $-(Z)-\alpha$-bisabolene epoxide, $10=$ cis- $(Z)-\alpha$-bisabolene epoxide, and $11=$ $n$-nonadecane). 
$\alpha$-bisabolene occurred at a lower concentration and the ratio of bisabolene epoxide isomers was greatly skewed in favor of the cis-isomer.

\section{Discussion}

Investigations by two of us (JRA \& WRL) indicate the male-specific $224 \mathrm{MW}$ isomers reported by French investigators to be attractive to $N$. viridula females $[8,9]$ are formed by dimerization of (E)-4-oxo-2-hexenal. Although the exact structure of these dimers has not been determined, the mass spectra and GC retention times of the two main $224 \mathrm{MW}$ compounds from heat-treated $(E)$-4-oxo2-hexenal are virtually identical to compounds detected in extracts of two other pentatomids ( $P$. connexivus and E. servus), and in an extract from the exuviae of a fifth-instar $N$. viridula nymph, all of which contained (E)-4-oxo-2-hexenal as a major component. Electron-impact mass spectra created to match those reported by Pavis [9], and entered into the computer library of our Finnigan GC-MS, were retrieved as the best-fit matches to the mass spectra for the (E)-4-oxo-2-hexenal dimers (Fig. 2, compounds 4 and 5; 94.8\% and $93.6 \%$, respectively, INCOS software processing).

Isolation of male-specific pheromone blends without contamination from the metathoracic scent gland secretion is difficult, even by the aeration method, because if just one bug emits its allomone during loading into the apparatus or dies during the sampling period, the sample will be overwhelmingly contaminated. The $N$. viridula extracts analyzed by the French researchers were prepared either by rinsing the walls of glass bottles that had contained bugs for $24 \mathrm{~h}$ or by rinsing the bugs themselves with hexane [9]. The cuticular rinses were most active in olfactometer tests [9], but were highly contaminated by metathoracic scent gland secretion containing (E)-4-oxo-2-hexenal $[9,17]$.

Hexanal in metathoracic scent gland secretions of coreid bugs (Heteroptera: Coreidae) gradually formed aldol condensation and trimerization products after extraction [18, 19]. Similarly, we suggest that the $(E)$-4-oxo-2-hexenal dimers are artifacts produced spontaneously from the primary secretory components. The greater abundance of the $224 \mathrm{MW}$ isomers in extracts from sexually mature $N$. viridula males versus immature males may be due to higher $(E)$-4-oxo-2-hexenal concentrations in the scent glands of mature males $[8,9]$. It seems unlikely that dimers of $(E)$-4-oxo-2-hexenal are part of the attractant pheromone of $N$. viridula since these compounds occur in conspecific nymphs, as well as other pentatomid nymphs and adults. Moreover, (E)-4-oxo-2-hexenal dimers were not detected in uncontaminated aeration extracts of $N$. viridula males that were attractive to the bugs and their tachinid parasite in the field [5].

The additional analyses of pheromone blends for $N$. viridula reported here substantiate earlier reports $[5,7]$ that geographically isolated pheromone strains of the insect exist. The determination that SGSB males from the Wakayama location express an epoxide ratio of 0.82 is consistent with previous determinations for a population from the southerly island Kyushu (trans- $/$ cis-epoxide $=0.97$ [7]), confirming that a Japanese strain exists whose males produce equivalent amounts of the bisabolene epoxide isomers. Contrary to an earlier report [6], the $N$. viridula males we sampled from Londrina, Brazil, produced cis- $(Z)-\alpha$-bisabolene-1,2epoxide $(6.7 \%)$, as well as the trans-epoxide isomer $(31.3 \%$, trans- $/$ cis-epoxide $=4.67)$. Males from a colony originating near Brasilia ( $c a$. $1200 \mathrm{~km}$ north of Londrina) produced relatively much more of the cis-epoxide isomer $(19.9 \%$, trans-/cis-epoxide $=2.28$ ), suggesting that even within Brazil there may be different $N$. viridula strains. The trans-/cis-epoxide ratio of 3.90 for Australian $N$. viridula males is within the range of ratios determined for those populations exhibiting a clear excess of trans-( $Z$ - $-\alpha$-bisabolene-1,2-epoxide (all populations except Japanese), and males from the Italian population of $N$. viridula exhibited the lowest ratio (2.16) for this group of populations.

While it seems clear that two or more different pheromone strains of $N$. viridula exist, the significance of the distinctive ratios of the major epoxide isomers is unclear. Field-tests of synthetic trans-/ cis-(Z)- $\alpha$-bisabolene-1,2-epoxide blends have been conducted in the U.S. and Brazil on a small scale, but very few bugs or tachinid parasites were attracted (Aldrich, unpublished data). The discovery that males of three Acrosternum spp., including $A$. aseadum, release ( $Z$ )- $\alpha$-bisabolene-1,2-epoxides in ratios essentially the reserve of those for most $N$. viridula populations, and that one U.S. species 
(A. pennsylvanicum) liberates a blend like Japanese $N$. viridula males [7], is evidence that unique ratios of these sesquiterpenoids might be involved in species isolation.

The native Japanese species, $N$. antennata, produces a blend of male-specific volatiles similar to those of most $N$. viridula populations, whereas $N$. viridula males from Japan express the most clearcut deviation from other conspecific populations. Geographically isolated populations of $N$. viridula produce somewhat different acoustical courtship signals $[10,20]$, and the songs of $N$. antennata are much different than the songs of $N$. viridula [10]. Nevertheless, interspecific mating occurs naturally between $N$. antennata and $N$. viridula in sympatric areas even though sperm is not transferred to the females [21, 22]. One interpretation of this situation is that pheromones and acoustical signals of these Nezara spp. are still diverging.

[1] W. A. Jones, Ann. Entomol. Soc. Am. 81, 262 (1988).

[2] H. Hokkanen, Ann. Entomol. Fenn. 52, 28 (1986).

[3] J. R. Aldrich, Ann. Rev. Entomol. 33, 211 (1989).

[4] V. E. Harris and J. W. Todd, Entomol. Exp. Appl. 27, 117 (1980).

[5] J. R. Aldrich, J. E. Oliver, W. R. Lusby, J. P. Kochansky, and J. A. Lockwood, J. Exp. Zool. 244, 171 (1987).

[6] R. Baker, M. Borges, N. G. Cooke, and R. H. Herbert, Chem. Commun. 1987, 414.

[7] J. R. Aldrich, W. R. Lusby, B. E. Marron, K. C. Nicolaou, M. P. Hoffmann, and L. T. Wilson, Naturwissenschaften 76, 173 (1989).

[8] C. Pavis and C. Malosse, C. R. Acad. Sci. Ser. III 303, 273 (1986).

[9] C. Pavis, Aspects de la communication pheromonale et de la sensibilite olfactive chez un Heteropere Pentatomidae: Nezara viridula (L.), Dissertation, Univ. Paris-Sud 1986.

[10] M. Kon, A. Oe, H. Numata, and T. Hidaka, J. Ethol. 6, 91 (1988).

[11] J. R. Aldrich, J. P. Kochansky, W. R. Lusby, and M. Borges, Z. Naturforsch. 46c, 264 (1991).

\section{Acknowledgements}

We thank Dr. Thomas J. Henry (Systematic Entomology Laboratory, USDA-ARS) for identification Acrosternum aseadum, and Dr. Jocelia Grazia (Departamento de Zoologia, Instituto de Biociencias, U.F.R.G.S. - Porto Alegre - RS) for determination of Podisus connexivus. We are grateful to Drs. J. E. Oliver and J. P. Kochansky, USDAARS, Beltsville, for synthesis of (Z)- $\alpha$-bisabolene and $(E)$-4-oxo-2-hexenal, respectively. Letizia Mattiacci, Giuliana Giangiuliani, and Stefano Colazza, of the Agricultural Entomology Institute, University of Perugia, were instrumental in preparing samples of Italian $N$. viridula; as were Vanice Lopes dos Santos, Debora Siqueira Moll, Regina Maria Alves, Vinicius Ferreira Carvalho, and Helio Moereira dos Santos for samples of Brazilian insects; and Akemi Oe helped prepare the Japanese samples. Mention of commercial products does not constitute an endorsement by the U.S. Department of Agriculture.

[12] J. R. Aldrich, M. P. Hoffmann, J. P. Kochansky, W. R. Lusby, J. E. Eger, and J. A. Payne, Environ. Entomol. 20, 478 (1991).

[13] M. Borges and J. R. Aldrich, Experientia 48, 893 (1992).

[14] F. Delay and G. Ohloff, Helv. Chem. Acta 62, 369 (1979).

[15] B. E. Marron and K. C. Nicalaou, Synthesis 1989, 537.

[16] J. P. Ward and D. A. Van Dorp, Recueil 88, 989 (1969).

[17] A. R. Gilby and D. F. Waterhouse, Proc. Roy. Soc. $162 \mathrm{~B}, 105$ (1965).

[18] J. T. Baker, J. D. Blake, J. K. MacLeod, D. A. Ironside, and I. C. Johnson, Aust. J. Chem. 25, 393 (1972).

[19] J. R. Aldrich, M. S. Blum, A. Hefetz, H. M. Fales, H. A. Lloyd, and P. Roller, Science 201, 452 (1978).

[20] V. E. Harris, J. W. Todd, J. C. Webb, and J. C. Benner, Ann. Entomol. Soc. Am. 75, 234 (1982).

[21] K. Kiritani, N. Hokyo, and J. Yukawa, Res. Popul. Ecol. 5, 11 (1963).

[22] M. Kon, A. Oe, and H. Numata, unpublished data. 